\title{
Relationship Between Functional Movement Screen and Some Athletic Abilities in Karate Athletes
}

\author{
Suat Yildiz \\ Correspondence: Manisa Celal Bayar Üniversitesi, Faculty of Sport Sciences, Turkey.
}

Received: May 17, 2018

doi:10.11114/jets.v6i8.3352

Accepted: June 4, 2018

Online Published: June 8, 2018

URL: https://doi.org/10.11114/jets.v6i8.3352

\begin{abstract}
In karate athletes, quality of movement and trunk control are important factors. Power output that is performed in short time requires functional movement capabilities. It's quite important to know that which athletic abilities are related to functional movement. Due to this concern, the aim of the study was to examine relationship between functional movement screen (FMS) and some athletic abilities.

20 male, 12 female karate athletes (Blue or higher belts; age: 16,06 $\pm 0,9$ years; training age: 7,5 $\pm 1,1$ years; weight: $63,06 \pm 11,6 \mathrm{~kg}$; height: $171,9 \pm 6,1 \mathrm{~cm}$ ) voluntarily participated in the study. Measurements have been taken on non-consecutive days in Functional Movement Screen (FMS) test battery, core stabilization test battery, back-leg extension isometric strength (BS), handgrip strength (HS), flexibility (S\&R) and vertical jumping (SJ).

The results showed that there is the significant relationship between FMS and $S \& R, S J$, core stabilization $(\mathrm{p}<0.01)$, and BS $(\mathrm{p}<0.05)$. There is no the significant correlation between HS. Due to the relationship between FMS Score and core stabilization, S\&R, SJ and BS.

It's recommended practicing all these abilities to increase the quality of movement. Likewise, functional movement levels should be increased to perform better these athletic abilities.
\end{abstract}

Keywords: fms; karate; core stabilization; athletic performance

\section{Introduction}

The notion of functional movement has been popular for some years. Definition of functional movement is to maintain proper mobility and stability while performing functional movement patterns (Okada, Huxel, \& Nesser, 2011). These movement patterns include sport-specific activities. In the sport, most of the movements are performed in different planes while using different joints and groups of muscle (Yıldız, Pınar, \& Gelen, 2017). Test batteries which are used to assess in the sport should be similar to movement patterns of sport or very close to it due to this reason Functional Movement Screen test batteries have become very popular recently (Kraus, Schutz, Taylor, \& Doyscher, 2014; Y1ldiz, Gelen, \& Erkan, 2014). Studies found that results of FMS tests have reliability (Kiesel, Plisky, \& Voight, 2007; Teyhen et al., 2012). FMS include 7 main and 3 clearance tests (Cook, 2010). Someone can have 21 points in total, between 0-3 points each of seven tests according to the quality of movements (Cook, 2010; Y1ldiz et al., 2017). It's thought that when the scores are high asymmetries and limitations of movement are weak (Cook, 2010). At the same time, this is the purpose of the test to evaluate limitations and asymmetries (Cook, 2010). In literature FMS has been used for several reasons to predict the risk of injuries (Kiesel et al., 2007), to investigate of the relationship between core stability, FMS and some performance parameters (Okada et al., 2011), predicting athlete's need in the off-season and developing appropriate training programs (Kiesel, Plisky, \& Butler, 2011).

In the Karate application of movements are performed in short times with rapid power outputs. These power outputs are performed properly to the karate and transferred from one segment of the body to another. Like most of any other sports, karate requires using ground reaction forces as a factor that affects the success. Lower body should be used effectively to execute kicks which are common movement in karate. To determinate athlete's levels are very important to observe lower body kinematics. In a study has compared karate athletes who compete in International and national level found that mae-geri kicking technique is performed with higher power-output in international karate athletes (Pozo, Bastien, \& Dierick, 2011). Another ability that affects elite karate athletes' performance is to have a stable body under static and dynamic conditions while performing punching which is sport specific movement pattern (Cesari \& Bertucco, 2008). Because punching can be started under static and dynamic conditions. Our study's purpose is to determinate FMS 
Scores and which other athletic capabilities have a relationship with functional movement.

\section{The Method}

The demographic features of the participants in our study are stated in Table 1.

32 karate athletes (blue belt and above) voluntarily participated in the study from the city of Sakarya in Turkey. We wanted that the athletes didn't exercise hardly within 24 hours before the applications and tests and eat at least two hours before. All athletes were informed about the risks and the benefits of their participating in this study and they signed the disclosure permission form before being applied any test. However, we moved along with the "Helsinki Declaration" in each process of the study.

Table 1. The demographic features of the participants

\begin{tabular}{lrrrrr}
\hline & $\mathrm{N}$ & Minimum & Maximum & \multicolumn{1}{c}{ Mean } & Std. Deviation \\
\hline Age & 32 & 15,00 & 18,00 & 16,0625 &, 94826 \\
Training Age & 32 & 6,00 & 11,00 & 7,5000 & 1,13592 \\
Height $(\mathrm{cm})$ & 32 & 160,00 & 183,00 & 171,8750 & 6,05219 \\
Weight $(\mathrm{kg})$ & 32 & 48,00 & 85,00 & 63,0625 & 11,57009 \\
\hline
\end{tabular}

Participant's performance data have been taken in functional movement screen score (FMS), squat jump (SJ), flexibility (S\&R), handgrip strength (HS), back and leg strength (BS), core stability (core), right lateral plank (LP-R), left lateral plank (LP-L), core flexion muscular endurance (crunch).

Squat jump (SJ), flexibility (S\&R), handgrip strength (HS), back and leg strength (BS), core stability (core), right lateral plank (LP-R), left lateral plank (LP-L), core flexion muscular endurance (crunch) tests were done after warmup which suggested by researchers (Gelen, 2010; Gelen, Meriç, \& Yıldız, 2010). Data which have been obtained from study correlated with Pearson Correlation test.

Trunk Flexor Endurance Test

This test evaluates endurance of deep trunk muscles. A platform is put back to the participant at the start of the test then while performing it is taken $10 \mathrm{~cm}$ away from the participant. While performing testing procedure back and legs angles of the participant are 60 and 90 degrees in a row. Participant isometrically performs test until he/she doesn't maintain proper position and fatigues (McGill, Childs, \& Liebenson, 1999).

Trunk Lateral Endurance Test

This test evaluates endurance of lateral trunk muscles. During testing procedure participant isometrically tries to keep his/her spine in a stable position until participant fatigues and don't maintain his/her starting position (McGill, Childs, \& Liebenson, 1999).

Trunk Extensor Endurance Test

This test evaluates endurance of trunk extensors. A participant puts his/her lower back edge of the table lies down to the ground and place hands on the anterior shoulder. During testing procedure participants feet are locked. Test procedure continues until participant doesn't maintain his/her starting position (McGill, Childs, \& Liebenson, 1999).

Functional Movement Screen (FMS)

FMS consists of 10 test batteries including 7 main and 3 clearance tests. Participant gets between 0-3 points according to the quality of movement. Participants get 3 points when they perform excellent movement pattern, 2 points they perform with a few compensations but completes movement and 1 point they don't complete movement and 0 points pain is present (Cook, 2010; Yıldız et al., 2017).

\section{The Results}

Results have been obtained from study has been shown in Table 2 and Table 3.

Table 2. Descriptive Statistics

\begin{tabular}{llll}
\hline & Mean & Std. Deviation & N \\
\hline S\&R & 31,4063 & 9,71151 & 32 \\
SJ & 18,1875 & 5,02534 & 32 \\
HG & 38,7563 & 9,70766 & 32 \\
Crunch & 189,2188 & 90,08332 & 32 \\
BS & 158,4375 & 55,14683 & 32 \\
LP-R & 140,1541 & 76,08931 & 32 \\
LP-L & 146,1209 & 76,50661 & 32 \\
BE & 195,7666 & 74,29078 & 32 \\
Core & 167,8151 & 65,27939 & 32 \\
FMS & 15,8750 & 2,05960 & 32 \\
\hline
\end{tabular}


Very significant correlation has been found between FMS and flexibility and Squat Jump and Trunk Stabilization $(\mathrm{p}<0.01)$, Significant correlation between FMS and Back-Leg strength and hand grip strength ( $<<0.05)$.

Table 3. Correlations of athletic performance and FMS

\begin{tabular}{|c|c|c|c|c|c|c|c|c|c|c|c|}
\hline & & S\&R & SJ & HG & Crunch & BS & LP-R & LP-L & BE & Core & FMS \\
\hline \multirow{2}{*}{ S\&R } & $r$ value & 1 &, $368^{*}$ &,- 029 &, $686^{* * *}$ &, $423^{*}$ & $405^{*}$ & ,327 & $463^{* * *}$ &, $583^{* * *}$ &, $740^{* * *}$ \\
\hline & $p$ value & & 038 & 873 & 000 & 016 & 021 & 067 & 008 & .000 & 000 \\
\hline \multirow{2}{*}{ SJ } & $r$ value &, $368^{*}$ & 1 &, $599^{* * *}$ & $508^{* * *}$ & $754^{* * *}$ & $476^{* * *}$ &, $537^{* *}$ & , 188 &, $525^{* *}$ &, $520^{* *}$ \\
\hline & $p$ value &, 038 & &, 000 & ,003 &, 000 & ,006 & ,002 & ,304 & ,002 & ,002 \\
\hline \multirow{2}{*}{ HG } & $r$ value &,- 029 &, $599^{* * *}$ & 1 & ,099 & $755^{\text {*** }}$ &,- 050 & 183 &,$- 397^{*}$ &,- 040 & 049 \\
\hline & $p$ value &, 873 &, 000 & & ,592 & ,000 & ,787 & 317 & 025 &, 829 &, 788 \\
\hline \multirow{2}{*}{ Crunch } & $r$ value & $686^{* * *}$ &, $508^{* * *}$ & ,099 & 1 & $411^{*}$ & $485^{* *}$ & 470 ** & $406^{*}$ & $739^{* * *}$ & $746^{* *}$ \\
\hline & $p$ value & 000 & ,003 &, 592 & & 020 & ,005 & ,007 & 021 &, 000 & ,000 \\
\hline \multirow{2}{*}{ BS } & $r$ value & $423^{*}$ & $754^{* * *}$ & $755^{\text {** }}$ &, $411^{*}$ & 1 & $368^{*}$ & $461^{* * *}$ &, 085 &, $408^{*}$ &, $357^{*}$ \\
\hline & $p$ value & ,016 & ,000 & ,000 & ,020 & & ,038 & ,008 & ,644 & ,020 & ,045 \\
\hline \multirow{2}{*}{ LP-R } & $r$ value & $405^{*}$ & $476^{* *}$ &,- 050 & $485^{\text {** }}$ &, $368^{*}$ & 1 &, $885^{* *}$ & $695^{* *}$ &, $916^{* *}$ &, $551^{* *}$ \\
\hline & $p$ value & ,021 & ,006 & ,787 & ,005 & ,038 & & ,000 & ,000 &, 000 & ,001 \\
\hline \multirow{2}{*}{ LP-L } & $r$ value & ,327 &, $537^{* *}$ &, 183 & $470^{* *}$ & $461^{* * *}$ &, $885^{* *}$ & 1 &, $544^{* *}$ &, $868^{* *}$ &, $571^{* *}$ \\
\hline & $p$ value & 067 & ,002 &, 317 & 007 & ,008 &, 000 & & ,001 &, 000 &, 001 \\
\hline \multirow{2}{*}{ BE } & $r$ value & $463^{* *}$ & 188 &,$- 397^{*}$ & $406^{*}$ &, 085 &, $695^{* *}$ &, $544^{* * *}$ & 1 & $786^{* *}$ &, $573^{* *}$ \\
\hline & $p$ value &, 008 & 304 &, 025 & 021 & 644 &, 000 & ,001 & & 000 & 001 \\
\hline \multirow{2}{*}{ Core } & $r$ value &, $583^{* *}$ &, $525^{\text {** }}$ &,- 040 & 739 ** & $408^{*}$ & $916^{\text {*** }}$ & $868^{* * *}$ &, $786^{* * *}$ & 1 & $748^{* * *}$ \\
\hline & $p$ value &, 000 &, 002 &, 829 &, 000 & ,020 &, 000 &, 000 &, 000 & &, 000 \\
\hline \multirow{2}{*}{ FMS } & $r$ value &, $740^{* *}$ &, $520^{* *}$ &, 049 & $746^{* *}$ &, $357^{*}$ & $551^{* * *}$ & $571^{* * *}$ & $573^{* *}$ &, $748^{* *}$ & 1 \\
\hline & $p$ value &, 000 &, 002 & ,788 &, 000 &, 045 &, 001 &, 001 &, 001 &, 000 & \\
\hline
\end{tabular}

*. Correlation is significant at the 0.05 level (2-tailed).

**. Correlation is significant at the 0.01 level (2-tailed). 5. The Discussion and the Results

In our study, the significant correlation was found between FMS scores and trunk stabilization ( $<<0.01$ ). FMS test battery gives us the opportunity to assess Trunk stabilization in several tests including Deep squat, Hurdle step, In-line Lunge, Rotary Stability, Active Straight Leg Raise, Push-up stability (Cook, 2010; Yıldız et al., 2017). If the athlete has a minimal or no trunk movement it is assumed that athlete will get higher points (Cook, 2010). In a study has been recently published showed that (Bagherian, Ghasempoor, Rahnama, \& Wikstrom, 2018) 8 weeks core training programs result in increasing FMS scores. In the Karate athletes require trunk stabilization to increase the quality of movement. Because in the karate athletes need explosive movements patterns such as punching and kicking. While performing these lower and upper extremity movements, trunk activation starts earlier whether the movement of limbs fast or not (Hodges \& Richardson, 1997a, 1997b). If the athlete has a functional body it means energy expenditure is low and during application of movements, there will not be an additional force generated by the tension of other muscle out of athlete's external force.

The significant relationship has been found between FMS and Squat Jump ( $\mathrm{p}<0.05)$. In the Karate kicks to the head zones bring more points (Federation, 2015). To be taken these points, the athlete should apply more force to the ground and jump up higher levels to make kick easier. While applying forces to the ground and determining jumping height one of the most important body segments is ankle ROM (Yun et al., 2016). In the FMS, this ability can be measured with Deep squat (Passive Dorsiflexion) and Hurdle Step (Active Dorsiflexion). While performing these tests we could evaluate angles of dorsiflexion as well as the quality of movement. If the athlete has a quality movement pattern it will be easier to perform this ability.

Hamstring muscles flexibility is another factor that affects kicking to the head zones. The athlete should have great flexibility to perform the kicking ability. If the athlete doesn't have enough ROM; it will be very hard both acceleration of kicking with knee extensor and braking of the kicking with the knee flexor (Pozo et al., 2011) to stop movement. In the FMS there is active straight leg raise test that we can directly assess ROM of hip and knee joints. Elasticities of gluteus maximus, hamstring and gastroc-soleus muscles which determinate quality of the kicking can be assessed with this test.

Back- leg strength is an athletic skill that requires the application of the force to the ground and then transferring generated force to the upper segments of the body (Zorba et al., 2010). In the martial arts to produce an effective strength we should use ground's reaction forces (Estevan, Jandacka, \& Falco, 2013). Sometimes to perform punching activities we should transfer the forces to upper segments of the body by using Core muscles (Shinkle, Nesser, Demchak, \& McMannus, 2012). Assessment of this ability's quality can be observed through the deep squat. We think that there is a relationship between deep squat and back-leg strength performances.

\section{References}

Bagherian, S., Ghasempoor, K., Rahnama, N., \& Wikstrom, E. A. (2018). The Effect of Core Stability Training on Functional Movement Patterns in Collegiate Athletes. J. Sport Rehabil, 1-22. https://doi.org/10.1123/jsr.2017-0107 
Cesari, P., \& Bertucco, M. (2008). Coupling between punch efficacy and body stability for elite karate. J. Sci. Med. Sport, 11(3), 353-356. https://doi.org/10.1016/j.jsams.2007.05.007

Cook, G. (2010). Movement: Functional Movement Systems: Screening, Assessment, Corrective Strategies: On Target Publications, LLC.

Estevan, I., Jandacka, D., \& Falco, C. (2013). Effect of stance position on kick performance in taekwondo. J. Sports Sci., 31(16), 1815-1822. https://doi.org/10.1080/02640414.2013.803590

Federation, W. K. (2015). Kata and Kumite Competition Rules Revision 9.0 Effective From 1.1.2015. Retrieved from https://www.wkf.net/pdf/wkf-competition-rules-version9-2015-en.pdf

Gelen, E. (2010). Acute effects of different warm-up methods on sprint, slalom dribbling, and penalty kick performance in soccer players. J. Strength Cond. Res., 24(4), 950-956. https://doi.org/10.1519/JSC.0b013e3181cb703f

Gelen, E., Meriç, B., \& Yıldız, S. (2010). Farklı Isınma Protokollerinin Sürat Performansına Akut Etkisi. Türkiye Klinikleri J. Sports Sci., 2(1), 6.

Hodges, P. W., \& Richardson, C. A. (1997a). Contraction of the abdominal muscles associated with movement of the lower limb. Phys. Ther, 77(2), 132-142; discussion 142-134.

Hodges, P. W., \& Richardson, C. A. (1997b). Relationship between limb movement speed and associated contraction of the trunk muscles. Ergonomics, 40(11), 1220-1230. https://doi.org/10.1080/001401397187469

Kiesel, K., Plisky, P. J., \& Voight, M. L. (2007). Can Serious Injury in Professional Football be Predicted by a Preseason Functional Movement Screen? N. Am. J. Sports Phys. Ther., 2(3), 147-158.

Kiesel, K., Plisky, P., \& Butler, R. (2011). Functional movement test scores improve following a standardized off-season intervention program in professional football players. Scand J. Med. Sci. Sports, 21(2), 287-292. https://doi.org/10.1111/j.1600-0838.2009.01038.x

Kraus, K., Schutz, E., Taylor, W. R., \& Doyscher, R. (2014). Efficacy of the functional movement screen: a review. J Strength Cond Res, 28(12), 3571-3584. https://doi.org/10.1519/JSC.0000000000000556

McGill, S. M., Childs, A., \& Liebenson, C. (1999). Endurance times for low back stabilization exercises: clinical targets for testing and training from a normal database. Arch. Phys. Med. Rehabil., 80(8), 941-944. https://doi.org/10.1016/S0003-9993(99)90087-4

Okada, T., Huxel, K. C., \& Nesser, T. W. (2011). Relationship Between Core Stability, Functional Movement, and Performance. The Journal of Strength \& Conditioning Research, 25(1), 252-261. https://doi.org/10.1519/JSC.0b013e3181b22b3e

Pozo, J., Bastien, G., \& Dierick, F. (2011). Execution time, kinetics, and kinematics of the mae-geri kick: comparison of national and international standard karate athletes. J. Sports Sci., 29(14), 1553-1561. https://doi.org/10.1080/02640414.2011.605164

Shinkle, J., Nesser, T. W., Demchak, T. J., \& McMannus, D. M. (2012). Effect of core strength on the measure of power in the extremities. J. Strength Cond. Res., 26(2), 373-380. https://doi.org/10.1519/JSC.0b013e31822600e5

Teyhen, D. S., Shaffer, S. W., Lorenson, C. L., Halfpap, J. P., Donofry, D. F., Walker, M. J., ... Childs, J. D. (2012). The Functional Movement Screen: A Reliability Study. Journal of Orthopaedic \& Sports Physical Therapy, 42(6), 530-540. https://doi.org/10.2519/jospt.2012.3838

Yıldız, S., Gelen, E., \& Erkan, E. (2014). Examining The Relationship Between Antropometric Characteristics, Athletic Performance And Functional Movement On Elite Level Of Karate Players. 13. Uluslararası Spor Bilimleri Kongresi, 7-9 Kasım, Konya, Türkiye

Yıldız, S., Pınar, S., \& Gelen, E. (2017). Çocuk Tenisçilerde Fonksiyonel Antrenman. Lambert Academic Publishing, Mauritus, Germany, 2017.

Yun, S. J., Kim, M. H., Weon, J. H., Kim, Y., Jung, S. H., \& Kwon, O. Y. (2016). Correlation between toe flexor strength and ankle dorsiflexion ROM during the countermovement jump. J. Phys. Ther. Sci., 28(8), 2241-2244. https://doi.org/10.1589/jpts.28.2241

Zorba, E., Özkan, A., Akyüz, M., Harmancı, H., Taş, M., \& Şenel, Ö. (2010). Güreşçilerde bacak hacmi, bacak kütlesi, anaerobik performans ve bacak kuvveti arasındaki ilişki. Uluslararası İnsan Bilimleri Dergisi, 7(1), 83-96.

\section{Copyrights}

Copyright for this article is retained by the author(s), with first publication rights granted to the journal.

This is an open-access article distributed under the terms and conditions of the Creative Commons Attribution license which permits unrestricted use, distribution, and reproduction in any medium, provided the original work is properly cited. 